\title{
Detecting the vanishing populations of the highly endangered Darwin's fox, Pseudalopex fulvipes
}

\author{
Carles Vilà ${ }^{1}$, Jennifer A. Leonard ${ }^{1}$, Agustín Iriarte ${ }^{2}$, Stephen J. O’Brien ${ }^{3}$, Warren E. Johnson ${ }^{3}$ and Robert K. Wayne $^{1}$ \\ ${ }^{1}$ Department of Organismic Biology, Ecology and Evolution, University of California, Los Angeles, CA 90095-1606, USA \\ Current address, C. Vila: Department of Evolutionary Biology, Uppsala University, Norbyvägen 18D, S-75236 Uppsala, Sweden \\ Current address, J. A. Leonard: Genetics Program, Department of Systematic Biology, National Museum of Natural History, Smithsonian Institution, \\ 3001 Connecticut Ave. NW, Washington, DC 20008-0551, USA \\ ${ }^{2}$ Servicio Agricola y Ganadero, Ave. Bulnes 140, Santiago, Chile \\ ${ }^{3}$ Laboratory of Genomic Diversity, National Cancer Institute-FCRDC, Frederick, Maryland 21702-1201, USA
}

(Received 11 February 2003; accepted 1 October 2003)

\begin{abstract}
Darwin's fox (Pseudalopex fulvipes) is known to survive only on Chiloé Island off the coast of southern Chile and in Nahuelbuta National Park, $600 \mathrm{~km}$ to the north in mainland Chile. The Valdivian coastal forest, in which the Darwin's fox lives, historically spanned from Nahuelbuta National Park southward past Chiloé Island on the mainland. Furthermore, the forest on Chiloé Island was connected to the mainland forest by a land bridge for much of the Pleistocene. Thus, the distribution of Valdivian forest suggests that the historic range of Darwin's fox may have been much larger. We searched the remnant pockets of coastal forest on mainland Chile using live traps, non-invasive techniques and interviews to look for new populations of the critically endangered Darwin's fox. Although no Darwin's fox was captured, evidence of a new population near Punta Chanchán was found.
\end{abstract}

\section{INTRODUCTION}

The Darwin's fox (Pseudalopex fulvipes) is a small canid (2-4 kg: Yahnke et al., 1996) that lives in the coastal temperate rainforest of southern Chile. When Charles Darwin collected the first specimen on 6 December 1834 on Chiloé Island, a few kilometers off the coast of Chile (Fig. 1), he noticed, as reported by local inhabitants, that this fox was morphologically distinguishable from the mainland foxes (Darwin, 1839). However, although Darwin's foxes have shorter legs, a smaller body and darker colour than mainland foxes, they were considered, taxonomically, only as an insular subspecies of the mainland chilla fox (P. griseus; see Redford \& Eisenberg, 1992; Wilson \& Reeder, 1993; Nowak, 1999). More recently, a continental population of Darwin's fox that lives in sympatry with chilla and culpeo (P. culpaeus) foxes was discovered (Medel, Jiménez \& Jaksić, 1990). This finding, combined with subsequent molecular genetic analyses (Yahnke et al., 1996), confirmed that the Darwin's fox is a distinct species that diverged from the common ancestor of chilla and culpeo foxes in the Pleistocene.

Of all extant canids, Darwin's fox has one of the smallest known distributions, being limited to forested areas on the island of Chiloé and to a continental population

All correspondence to: Warren E. Johnson. Tel: 301-846-7483; FAX: 301-846-6327; E-mail: johnsonw@ncifcrf.gov in Nahuelbuta National Park, a $68 \mathrm{~km}^{2}$ protected area about $600 \mathrm{~km}$ north of the island. An estimated 5078 foxes inhabit this mainland park (Cofrè \& Marquet, 1999; Jiménez \& McMahon, in press). Since the fox is believed to be an obligate forest species (Jaksic et al., 1990; Medel et al., 1990) and the Park is surrounded by highly degraded habitat, this population is completely isolated (Jiménez \& McMahon, in press). The population in Chiloé is estimated to total about 250 individuals and the species is considered to be Critically Endangered in the IUCN Red List (Jiménez \& McMahon, in press).

To explain the presence of Darwin's fox on Chiloé Island and in Nahuelbuta National Park, Yahnke et al. (1996) argued that these populations are relicts of a once more-widely distributed species. In the late Pleistocene, Chiloé Island was connected to mainland Chile by a land bridge that was severed about 15000 years ago when the sea level rose following the last glaciation (Villagrán, 1988). The coastal Valdivian forest ecosystem remained both on the island and the mainland. However, in historic times, the more extensive forest on the mainland was heavily impacted and today only small patches of primary forest remain along the coastal range. Presumably, Darwin's fox vanished from the mainland with the loss of the native forest and currently remains only in Nahuelbuta National Park. However, human activity and land use is concentrated in the central valley between the coastal range and the Andes, leaving some patches of 


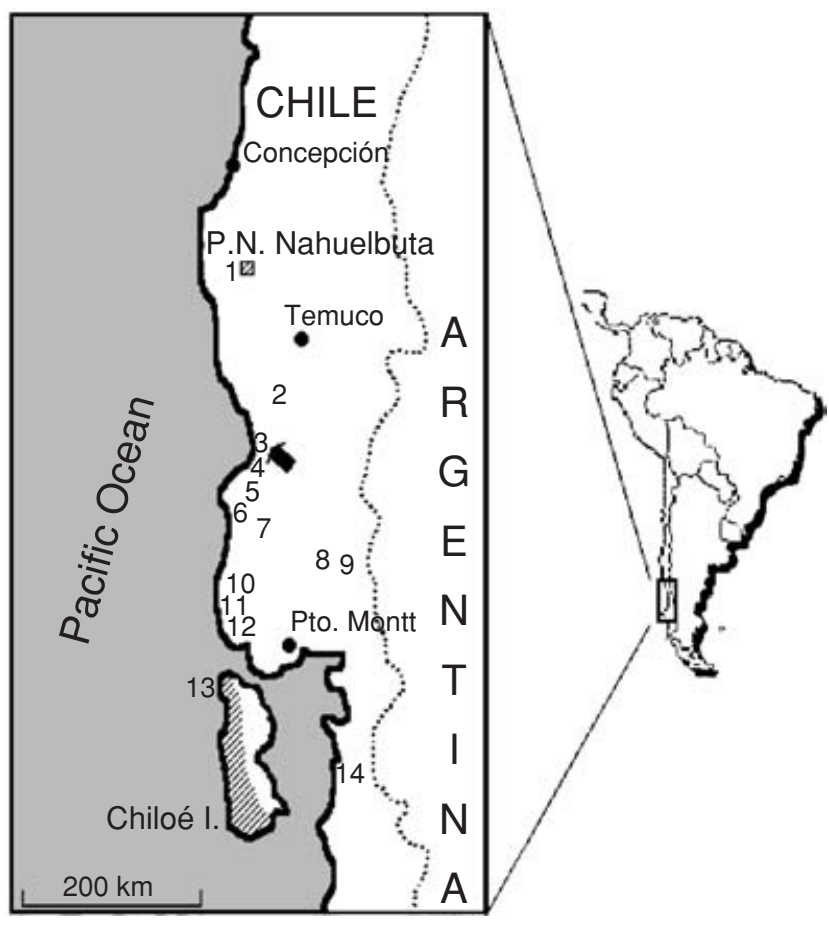

Fig. 1. Geographical distribution of sampling localities. Numbers correspond to those in Table 1. Shading indicates approximate distribution of Darwin's foxes on Chiloé Island and in Nahuelbuta National Park (Jiménez \& McMahon, in press). The arrow indicates Punta Chanchán (location number 3), where evidence of Darwin's foxes was found.

undisturbed, relict forest habitat along the coast between Nahuelbuta National Park and Chiloé Island. These areas are not densely populated and are largely inaccessible. Consequently, fox populations could have survived in the coastal ranges of southern Chile just as they have in Nahuelbuta National Park.

The goal of this study was to search for undiscovered populations of Darwin's foxes between Nahuelbuta National Park and Chiloé Island and on mainland areas west of Chiloé Island. To establish direct evidence for the presence of Darwin's foxes we used live traps and recently developed non-invasive sampling techniques (Kohn \& Wayne, 1997; Reed et al., 1997; Palomares et al., 2002), along with information collected from interviews with local residents, researchers and resource managers. The rapid destruction of forests in southern Chile and the subsequent loss of biodiversity (Rau \& Gantz, 2001) demand swift action to preserve any surviving populations, if they exist. Our results demonstrate the effectiveness of combined field and genetic techniques in documenting the persistence of endangered populations.

\section{MATERIALS AND METHODS}

Darwin's fox, as well as chilla and culpeo foxes, have sometimes been considered to be members of the genus Dusicyon. However, following Nowak (1999), in this study we refer to them as Pseudalopex.

\section{Trapping and sample collection}

Because Darwin's fox is a forest specialist, we focused on areas with reasonably intact and extensive fragments of native forest or dense secondary forests. The survey was conducted during January to March 1996 in 14 localities (Table 1, Fig. 1), including two localities (8 and 9 in Table 1) outside the coastal ranges where the efficiency of the trapping methods for foxes was assessed. From Chiloé Island (locality 13), we sampled two Darwin's foxes that suffered natural mortality. Faeces from Chiloé Island (locality 13) were collected in November 1993, including one from a captive Darwin's fox, which was used as a control. We terminated sampling at locality 12 when, after initial exploration, we discovered that the forest was degraded. In total, eight localities between Nahuelbuta National Park and Chiloé Island were extensively surveyed as well as one locality on the mainland east of Chiloé Island.

Local residents were interviewed to gather information about the existence of areas with well-preserved forests and populations of foxes similar in appearance to Darwin's foxes. These interviews led to the location of two dried skins of Pseudalopex, from localities 3 and 11, from which samples were obtained. At each one of the studied localities, we set leg-hold traps (Victor $1.5^{\prime \prime}$ ) until Pseudalopex foxes were captured (see Table 1) or for 35 nights. Traps were set in forest clearings and edges and along trails inside forests. Foxes were attracted using commercially available scents and lures or small pieces of rotten meat. The efficiency of this trapping method for foxes had been tested by W.E.J. in a diversity of locations and was additionally assessed at localities 8 and 9, where four canids were trapped in a period of 121 trap-nights (Table 1).

Since the trapping of carnivores inside the forest proved extremely difficult and the success rate was low (see below), sampling within thick forests consisted primarily of collecting faeces along small game trails. Faeces were stored dry and then frozen upon arrival in the USA.

\section{Genetic analyses}

DNA was extracted from the faeces using a silica-based method (e.g. Kohn et al., 1995) or the IsoQuick kit (Orca Research Inc., Bothell, WA: e.g. Kohn et al., 1999). Negative controls were included in each batch of extractions. DNA extractions were performed on each scat one to four times. DNA was extracted from blood or tissue samples using the phenol-chloroform extraction technique (Sambrook, Fritsch \& Manatis, 1989). First, polymerase chain reactions (PCR) were performed on all faecal samples with the Pseudalopex specific mitochondrial DNA (mtDNA) control region primers: L110129 5'-ATT CCT AAA ACC CCC TCC CC and H274251 5'-CCC TTA TTG AC TAA GTG ATA TGC. Due to a very low rate of success, the more universal cytochrome $b$ primers, carnCB53 5'-CCA ATG TTT CAT GTT TCT GGG A and carnCB58 5'- CCT ATT CCT AGC CAT ACA CTA CA (Leonard, Wayne \& Cooper, 
Table 1. Location, trapping effort (trap-nights), captured canid specimens and number of scats collected in each sampling locality (see Fig. 1)

\begin{tabular}{|c|c|c|c|c|c|c|}
\hline & Locality & & Trap-nights & Captured & Scats & Notes \\
\hline 1 & Nat. Park Nahuelbuta & $37^{\circ} 51^{\prime} \mathrm{S}, 73^{\circ} 7^{\prime} \mathrm{W}$ & - & - & 6 & \\
\hline 2 & Sierra de Queule & $39^{\circ} 15^{\prime} \mathrm{S}, 73^{\circ} 0^{\prime} \mathrm{W}$ & 10 & - & 10 & Forest highly degraded \\
\hline 3 & Punta Chanchán & $39^{\circ} 21^{\prime} \mathrm{S}, 73^{\circ} 14^{\prime} \mathrm{W}$ & 64 & 2 P. griseus & 4 & $\begin{array}{l}\text { Description of possible } P \text {. fulvipes, } \\
\text { skin sample of } P \text {. fulvipes }\end{array}$ \\
\hline 4 & Cerro Oncol & $39^{\circ} 44^{\prime} \mathrm{S}, 73^{\circ} 18^{\prime} \mathrm{W}$ & 104 & - & 11 & \\
\hline 5 & Fundo Chaihuín & $40^{\circ} 1^{\prime} \mathrm{S}, 73^{\circ} 25^{\prime} \mathrm{W}$ & 68 & 1 P. griseus & 49 & $\begin{array}{l}\text { Description of possible (?) } \\
\text { P. fulvipes }\end{array}$ \\
\hline 6 & Nat. Park Alerce Costero & $40^{\circ} 8^{\prime} \mathrm{S}, 73^{\circ} 28^{\prime} \mathrm{W}$ & 80 & - & 27 & \\
\hline 7 & Fundo Llancacura & $40^{\circ} 18^{\prime} \mathrm{S}, 73^{\circ} 23^{\prime} \mathrm{W}$ & 38 & 1 C. familiaris & 2 & \\
\hline 8 & Rupanco Lake & $40^{\circ} 45^{\prime} \mathrm{S}, 72^{\circ} 33^{\prime} \mathrm{W}$ & 67 & 2 P. griseus & - & $\begin{array}{l}\text { (Outside presumed habitat of } \\
\text { P. fulvipes) }\end{array}$ \\
\hline 9 & Antillanca & $40^{\circ} 45^{\prime} \mathrm{S}, 72^{\circ} 10^{\prime} \mathrm{W}$ & 54 & $\begin{array}{l}1 \text { P. griseus, } \\
\quad 1 \text { C. familiaris }\end{array}$ & - & $\begin{array}{l}\text { (Outside presumed habitat of } \\
\text { P. fulvipes) }\end{array}$ \\
\hline 10 & San Pedro Bay & $40^{\circ} 55^{\prime} \mathrm{S}, 73^{\circ} 50^{\prime} \mathrm{W}$ & 9 & 2 P. griseus & 9 & \\
\hline 11 & Fundo Esperanza & $41^{\circ} 10^{\prime} \mathrm{S}, 73^{\circ} 50^{\prime} \mathrm{W}$ & 70 & - & 28 & P. griseus skin sample \\
\hline 12 & Los Muermos & $41^{\circ} 20^{\prime} \mathrm{S}, 73^{\circ} 43^{\prime} \mathrm{W}$ & 2 & - & - & $\begin{array}{l}\text { Forest almost completely } \\
\text { destroyed }\end{array}$ \\
\hline 13 & Ancud (Chiloé) & $41^{\circ} 52^{\prime} \mathrm{S}, 73^{\circ} 49^{\prime} \mathrm{W}$ & - & - & 4 & $\begin{array}{l}\text { Tissue samples from two dead } \\
\text { P. fulvipes }\end{array}$ \\
\hline \multirow[t]{2}{*}{14} & Chaitén & $43^{\circ} 10^{\prime} \mathrm{S}, 72^{\circ} 15^{\prime} \mathrm{W}$ & 38 & - & 2 & $\begin{array}{l}\text { Very low density of possible } \\
\text { evidence for foxes }\end{array}$ \\
\hline & & TOTAL: & 604 & & 152 & \\
\hline
\end{tabular}

Species identity of all foxes was confirmed by mtDNA control region sequencing (see Methods). Pseudalopex fulvipes, Darwin's fox; P. griseus, chilla fox; Canis familiaris, domestic dog.

2000 ), or the more cat specific cytochrome $b$ primers, CB53cat 5'-CCT CTT TTT GGC CAT ACA CTA C and CB58cat 5'-CCA ATG TTT CAT GTC TCT GAG A, were used (see Results, below). DNA extracted from blood or tissue was amplified with the primers ThrL15962 5'-CAA TTC CCC GGT CTT GTA AAC C and DLH16340 5'CCT GAA GTA GGA ACC AGA TG from Vilà et al. (1999). PCRs contained 1 U Taq polymerase (Promega), $1 \times$ reaction buffer provided by Promega, $2.5 \mathrm{mM} \mathrm{MgCl}_{2}$, $0.5 \mathrm{mM}$ dNTPs, $0.5 \mu \mathrm{M}$ each primer and $1 \mathrm{mM}$ bovine serum albumin (BSA) in $50 \mu \mathrm{l}$ with or without waxmediated hot starts. Reactions were run in a PerkinElmer Cetus PCR (Perkin-Elmer Cetus, Foster City, CA) thermo-cycler for 40 cycles of $94^{\circ} \mathrm{C}$ for $1 \mathrm{~min}, 45-52^{\circ} \mathrm{C}$ for $2 \mathrm{~min}$ and $72^{\circ} \mathrm{C}$ for $1.5 \mathrm{~min}$. Extraction negatives, as well as PCR negatives, were run in each reaction. PCR products were purified using UltraClean (Mo Bio Laboratories, Carlsbad, CA) and sequenced with PRISM dye labelled terminators (Perkin-Elmer Cetus, Foster City, CA) in a Perkin-Elmer 9600 PCR machine according to the manufacturer's protocol. Sequences were determined on an ABI 377 (Applied Biosystems, Foster City, CA, USA) sequencer at either the UCLA core sequencing facility (Los Angeles, CA), Laragen (Santa Monica, CA), or the National Cancer Institute (Frederick, MD).

We compared these sequences to the sequences obtained by Yahnke et al. (1996) and used their sequences for Darwin's, chilla and culpeo foxes, as well as our putative Darwin's fox sequences, to build phylogenetic trees. These trees were rooted with a hoary fox (Pseudalopex vetulus) sequence (Yahnke et al., 1996). The programme Modeltest version 3.06 (Posada \& Crandall, 1998) was used to estimate the model of sequence evolution that best fits this data set. The model selected was HKY assuming a proportion of invariable sites of 0.793 and a gamma distribution shape parameter of 1.039. A neighbour-joining phylogeny using the recommended model of evolution was constructed using the programme PAUP 4.0b10 (Swofford, 2002). Support for the different nodes in the phylogenetic tree was assessed with 1000 bootstrap pseudo-replicates. This programme was also used to build a maximum likelihood phylogeny using the quartet puzzling feature with 1000 puzzling steps and using the model of evolution estimated using Modeltest. Phylogenetic trees were also constructing using a Bayesian approach as implemented in the programme MrBayes v3.0B4 (Huelsenbeck \& Ronquist, 2001).

\section{RESULTS}

\section{Interviews}

The on-site search for evidence of Darwin's foxes was supplemented with information from interviews with residents about foxes in the area. In general, informants were unaware of any fox other than chilla and culpeo. Only at two locations ( 3 and 5) did interviewees indicate the presence of a third type of fox. We were unable to find any field evidence of Darwin's foxes at location 5 (see below). However, a veterinary student from Universidad 
Table 2. Species identification from faeces at each locality based on mtDNA cytochrome $b$ and/or control region sequences

\begin{tabular}{lcl}
\hline Locality & Scats sequenced & Identified \\
\hline 1 & 4 & Oncifelis guigna (2), Pseudalopex fulvipes (2) \\
2 & 6 & Oncifelis guigna (4), Ocifelis sp. (1), Pseudalopex (culpaeus?) (1) \\
3 & 1 & Oncifelis guigna (1) \\
4 & 8 & Oncifelis guigna (8) \\
5 & 33 & Oncifelis guigna (27), Oncifelis sp. (2), Canis familiaris (1), \\
& & Pseudalopex (griseus?) (1), prey: Abrothrix (longipilis?) (1), \\
& 17 & Geoxus valdivianus (1) \\
6 & 1 & Oncifelis guigna (12), Canis familiaris (1), prey: Abrothrix (longipilis?) (3) \\
& 4 & and unidentified rodent (1) \\
7 & 21 & Prey: unidentified rodent (1) \\
10 & 1 & Oncidalopex (griseus?) (4) \\
11 & 0 & Oncifelis guigna (1) \\
13 & & \\
14 & &
\end{tabular}

Only scats for which mtDNA was successfully amplified and sequenced are included. In some cases the mtDNA amplified corresponded to rodents ingested as prey (Abrothrix longipilis, Geoxus valdivianus, Rattus and unidentified rodents). The species identification of chilla (Pseudalopex griseus) and culpeo (P. culpaeus) foxes was not certain due to paraphyly (see Fig. 2).

Austral in Valdivia, conducting field work on cervids and with experience in the direct observation of wild canids indicated that he had observed a Darwin's fox-like canid on the road accessing Punta Chanchán, location 3 (Fig. 1). His observations led to our sampling of faeces and setting traps in the area. Moreover, we located a dry fox skin decorating the home of a resident of Punta Chanchán that was consistent with the traits of a Darwin's fox. This specimen had a dark pelage, with short ears and legs, small body size and weak orange colour on the legs (measurements and pictures are available upon request). According to the owner, it was a male, probably young, that had been killed a couple of years earlier in a forest with patches of pastures about $1 \mathrm{~km}$ from the coast. The mtDNA control region sequence from that skin corresponded to a Darwin's fox (see below).

One additional dry skin sample was obtained from one interviewee close to location 11. However, both morphological and genetic analyses indicated that this sample corresponded to a chilla fox (data not shown).

\section{Live trapping}

In 604 trap-nights we captured eight foxes at five localities (Table 1). All eight foxes were identified in the field as chilla foxes, which was later reaffirmed by mtDNA control region sequence comparison with those reported by Yahnke et al. (1996). However, chilla and culpeo fox sequences form a paraphyletic group and, therefore, the two species can not be distinguished on the basis of mtDNA sequence alone (see Fig. 2). Consequently, our trapping efforts found no direct evidence of the presence of Darwin's fox, including at localities 3 and 5 where a skin sample and indirect reports, respectively, suggested the presence of this species (see above). Three chilla foxes were captured in these two localities.

\section{Non-invasive sampling}

We collected 152 scats along trails and paths in 11 localities, including Nahuelbuta (Table 1). The scats were visually identified as small carnivore in origin and possibly deriving from foxes. We extracted DNA from the scats and amplified and sequenced a short fragment of the cytochrome $b$ and/or the control region of the mitochondrial genome. Mitochondrial DNA was successfully amplified and sequenced, at least partially, from 96 out of 137 samples tested $(70 \%)$. In nine instances $(9 \%)$ the mtDNA sequences corresponded to prey species (rodents: see Table 2). For the remaining 87 faecal samples, 74 produced sequences identified as kodkod (Oncifelis guigna), three corresponded with an unidentified cat species (probably kodkod, the sequence was not complete), and two were from domestic dog (Canis familiaris). Six faeces were from either chilla or culpeo foxes (Table 2). Two Pseudalopex scats, collected in Nahuelbuta National Park and for which only partial sequence was obtained, probably corresponded to Darwin's fox. The control faecal-sample collected from a captive Darwin's fox yielded a sequence matching the previously observed Darwin's fox haplotype, Dfu3 (Fig. 2).

A large number of faeces were collected in locality 5 due to the suggestion that Darwin foxes could be surviving there (see above). Thirty-three of these faeces were genetically analysed, but none of them could be identified as corresponding to Darwin's fox. Similarly, the only scat analysed in location 3 (where the skin of a Darwin's fox had been collected) corresponded to kodkod.

The scat analysis did not provide evidence of Darwin's fox outside Nahuelbuta National Park and Chiloé Island. Only $9 \%$ of the scats of identifiable origin were from foxes and at least $85 \%$ were from kodkods. Kodkods are a small, poorly-known cat that is restricted to 'south-central Chile 


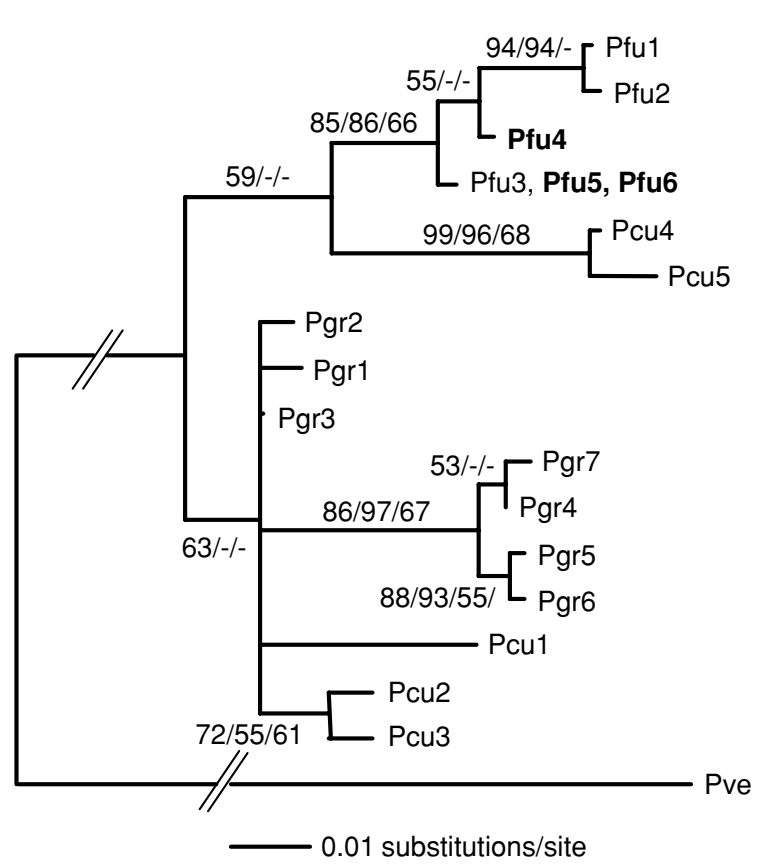

\section{Darwin's foxes}

Nahuelbuta National Park

Punta Chanchán

Chiloé Island

Chilla and culpeo foxes

Hoary fox

Fig. 2. Neighbour-joining phylogenetic tree of mtDNA control region sequences of Darwin's (Pfu), chilla (Pgr) and culpeo (Pcu) foxes. Similar trees were obtained using Bayesian and maximum likelihood (quartet puzzling) approaches. Support for the phylogeny is indicated by the nodes when higher than $50 \%$ and was assessed using 1000 neighbour-joining bootstrap replicates (first number), consensus of Bayesian trees (second number) and with 1000 puzzling steps (third number). The tree is rooted with hoary fox (Pve). All sequences derive from Yahnke et al. (1996) except Pfu-4, Pfu-5 and Pfu-6.

and adjacent Argentina in the Andean areas' (Redford \& Eisenberg, 1992).

\section{Other genetic samples}

A $314 \mathrm{bp}$ sequence of the mtDNA control region from the fox specimen from Punta Chanchán (Pfu4) and from the two fox samples collected on Chiloé Island (Pfu5 and Pfu6) were compared with the sequences obtained by Yahnke et al. (1996; see Table 3). The two Chiloé specimens had the same haplotype as the Chiloe Island haplotype, Dfu3, reported previously by Yahnke et al. (1996). However, Pfu4 differed from other Darwin's fox sequences at 2-4 sites $(0.7-1.3 \%)$. A phylogenetic tree rooted with hoary fox showed that Pfu4 clusters with the clade of Darwin's fox sequences and is basal to sequences from Nahuelbuta National Park (Fig. 2). This clade is well differentiated from chilla and culpeo fox sequences.

\section{DISCUSSION}

Our data provided limited support for the existence of Darwin's fox in mainland areas outside of Nahuelbuta National Park in recent times. A single specimen from Punta Chanchán was phenotypically and genetically assigned to Darwin's fox. Since mtDNA is maternally inherited, the presence of Darwin's fox sequences in this individual could indicate that presence of the species in the area or it could be the legacy of a past hybridisation
Table 3. Pairwise divergence between Darwin's fox sequences

\begin{tabular}{lllllll}
\hline & Pfu-1 & Pfu-2 & Pfu-3 & Pfu-4 & Pfu-5 & Pfu-6 \\
\hline Pfu-1 & - & 1 & 6 & 4 & 6 & 6 \\
Pfu-2 & 0.4 & - & 5 & 3 & 5 & 5 \\
Pfu-3 & 2.3 & 2.0 & - & 2 & 0 & 0 \\
Pfu-4 & 1.4 & 1.1 & 0.7 & - & 2 & 2 \\
Pfu-5 & 2.3 & 2.0 & 0.0 & 0.7 & - & 0 \\
Pfu-6 & 2.3 & 2.0 & 0.0 & 0.7 & 0.0 & - \\
\hline
\end{tabular}

The number of substitutions in $314 \mathrm{bp}$ mtDNA control region sequences are listed above the diagonal. Below the diagonal, the percentage of sequence divergence, assuming ${ }^{a} \mathrm{HKY}+\mathrm{I}+\mathrm{G}$ model of sequence evolution (see the text), is listed. Pfu-1 and Pfu-2 correspond to foxes from Nahuelbuta National Park and Pfu-3 to a fox from Chiloé Island in Yahnke et al. (1996). Pfu-4 corresponds to the fox sample from Punta Chanchán (location 3 in Fig. 1 and Table 1), while Pfu-5 and Pfu-6 refer to foxes from Chiloé Island sampled in this study.

event between a female Darwin's fox and a male chilla. However, the fact that the morphology of this individual (short black legs and ears, dark body, etc) and that of a fox seen by an informant in the same area (see above) were consistent with that of Darwin's foxes suggests that this is not likely to be the result of an ancient hybridisation. If Darwin's foxes had long ago disappeared from the area, successive backcrosses with chilla foxes would probably produce individuals with a morphology similar to the latter species (e.g. see Adams, Leonard \& Waits, 2003). 
Punta Chanchán is midway between Nahuelbuta National Park and Chiloé Island and is more than $200 \mathrm{~km}$ from either location. Thus, the specimen is unlikely to have resulted from individual dispersal. The control region sequence data provides additional support for this conclusion since the Punta Chanchán specimen has a different sequence to those found in foxes from Nahuelbuta or Chiloé Island. However, faecal surveys of Punta Chanchán and other localities remain inconclusive. Although a total of 87 faeces of forest dwelling carnivores were genetically assigned to species, only seven corresponded to a fox and only those collected inside Nahuelbuta were Darwin's fox. In a random sample of 87 scats we would expect to be able to have detected Darwin's fox with a $99 \%$ probability if its overall frequency was greater than $5 \%$ (binomial probability distribution). Therefore, the fact that none of the scats collected outside Nahuelbuta corresponded to Darwin's foxes indicates that the species, if present, is very rare.

Although we focused our trapping efforts on forested areas, where Darwin's foxes are more likely to be present (Jaksić et al., 1990; Medel et al., 1990), all foxes that were captured were on the edge or outside of forested areas. For example, at locality 4 , no foxes were caught in 104 trap-nights (Table 1). This could indicate that Darwin's foxes were either not drawn to the lures we used or were not present. A lack of interest in the lures seems unlikely since similar techniques have been used to capture them in Nahuelbuta National Park and on Chiloé Island (W.E.J., pers. obs.). Darwin's fox has a highly opportunistic diet that includes mammals, birds, reptiles, amphibians, insects, shellfish, algae, carrion, garbage, berries and seeds (Jaksić et al., 1990; Jiménez et al., 1991). In addition, Darwin's foxes often exist in close proximity to people and domestic dogs and, thus, are not expected to show strong avoidance of humans. In Chiloé they sometimes enter houses at night in search for food and habituate easily to people (W.E.J., pers. obs.; Jiménez \& McMahon, in press). Furthermore, the areas we surveyed were not subject to predator control programmes or hunting by locals and, thus, foxes were unlikely to have been trap shy. Therefore, the most consistent explanation of our results is that Darwin's foxes are rare or absent in the areas where we placed traps.

Another factor in the absence of Darwin's fox is that chilla and cupleo foxes may competitively exclude their smaller relative (e.g. Mech, 1970; Tannerfeldt, Elmhagen \& Angerbjorn, 2002). In support of this hypothesis, park personnel at Nahuelbuta National Park have described instances of chilla foxes attacking and chasing away Darwin's foxes. Consequently, Darwin's foxes may seek refuge and still persist in dense forest, but perhaps only in the rainforest core and at extremely low population densities. In these circumstances, species identification from scats may be the most efficient method of detecting Darwin's foxes. However, an unexpected problem was the dominance of kodkod faeces in our collection. In future surveys, in order to collect a larger number of fox scats, either a larger number of faeces needs to be collected or better field methods for excluding kodkod faeces from collection need to be employed. Considering the difficulty of finding faeces in heavily forested areas, dogs trained to detect fox faeces might be an effective strategy (e.g. Smith et al., 2001).

Based on the mtDNA sequences described for Darwin's foxes (Yahnke et al., 1996), the three foxes from Chiloé Island shared the same haplotype, whereas the three sequences from mainland foxes (two from Nahuelbuta National Park and one from Punta Chanchán) corresponded to three distinct haplotypes (see Table 3 \& Fig. 2). Sample sizes are small, but the results suggest that the island population, although it is larger than the mainland population, may have comparably less genetic variability and may have experienced genetic loss relative to those populations on the mainland. Furthermore, as suggested previously (Yahnke et al., 1996), mainland populations appear to be differentiated from those on the island and our results suggest that, to some degree, mainland populations may be differentiated from each other as well (Fig. 2). Hence, much of the genetic legacy on the mainland has been lost due to extinction of populations. However, these conclusions must be taken with caution until a larger sample size is available for confirmation.

\section{Conservation implications}

Our survey provides evidence that other mainland Darwin's fox populations existed recently in some native forest fragments along the coastal mountain range of southern Chile. However, we found no evidence of surviving individuals. Given that the island population of Darwin's foxes may have reduced genetic variability and that both the populations in Nahuelbuta National Park and on Chiloé Island are endangered, it is critically important to determine if any relict (and potentially genetically divergent) population still survives in the wellpreserved forest tracks near Punta Chanchán, north of Valdivia. These forests are increasingly being exploited and fragmented. To help prioritize and rationalize the establishment of protected areas in these unique coastal mountain ranges, the existence or extinction of Darwin's fox needs to be established. Our survey suggests that one effective strategy for doing so would involve extensive capture efforts and collection of faeces, possibly with the use of trained dogs to increase recovery of fox scat in dense forest. For elusive and rare species, such efforts may provide the only definitive assessment of extinction.

\section{Acknowledgements}

Mario Castellanos and Isabel Amorim helped in the field surveys. The Sevicio Agrícola y Ganadero of Chile provided all the permits required to do the field research. David Martínez and Jaime Rau offered logistic support from the University of Los Lagos, Osorno. The National Geographic Society (USA) provided economic support for this research and the Spanish Ministry for Science and Education supported C.V. 


\section{REFERENCES}

Adams, J. R., Leonard, J. A. \& Waits, L. P. (2003). Widespread occurrence of a domestic dog mitochondrial DNA haplotype in southeastern US coyotes. Mol. Ecol. 12: 541-546.

Cofré, H. \& Marquet, P. A. (1999). Conservation status, rarity, and geographic priorities for conservation of Chilean mammals: an assessment. Biol. Conserv. 88: 53-68.

Darwin, C. (1839). Journal of researches into the geology and natural history of the various countries visited by H.M.S. Beagle, under the command of Captain Fitzroy, R.N. from 1832-1836. London: Henry Colburn.

Huelsenbeck, J. P. \& Ronquist, F. (2001). MrBAYES: Bayesian inference of phylogenetic trees. Bioinformatics 17: 754-755

Jaksić, F. M., Jiménez, J. E., Medel, R. G. \& Marquet, P. A. (1990). Habitat and diet of Darwin's fox (Pseudalopex fulvipes) on the Chilean mainland. J. Mammal. 71: 246-248.

Jiménez, J. E., Marquet, P. A., Medel, R. G. \& Marquet, P. A. (1991). Comparative ecology of Darwin's fox (Pseudalopex fulvipes) in mainland and island settings of southern Chile. Rev. Chilena Hist. Nat. 63: 177-186.

Jiménez, J. E. \& McMahon, E. (in press). Darwin's fox (Pseudalopex fulvipes). In Canids: foxes, wolves, jackals and dogs. Status survey and conservation action plan. Sillero-Zubiri, C., Hoffmann, M. \& Macdonald, D. W. (Eds). Gland, Switzerland: IUCN/SSC Canid Specialist Group.

Kohn, M. H. \& Wayne, R. K. (1997). Facts from feces revisited. TREE 12: $223-227$.

Kohn, M. K., Knauer, F., Stoffella, A., Schröder, W. \& Pääbo, S. (1995). Conservation genetics of the European brown bear - a study using excremental PCR of nuclear and mitochondrial sequences. Mol. Ecol. 4: $95-103$.

Kohn, M. K., York, E. C., Kamradt, D. A., Haught, G., Sauvajot, R. M. \& Wayne, R. K. (1999). Estimating population size by genotyping faeces. Proc. R. Soc. Lond. Ser. B 266: 657-663.

Leonard, J. A., Wayne, R. K. \& Cooper, A. (2000). Population genetics of ice age brown bears. Proc. Natl. Acad. Sci. USA 97: 1651-1654.

Mech, L. D. (1970). The wolf: the ecology and behavior of an endangered species. New York; Natural History Press.

Medel, R. G., Jiménez, J. E. \& Jaksić, F. M. (1990). Discovery of a continental population of the rare Darwin's fox, Dusicyon fulvipes (Martin, 1837) in Chile. Biol. Conserv. 51: 71-77.
Nowak, R. M. (1999). Walker's mammals of the world, vol. 1. 6th edn. Baltimore: Johns Hopkins University Press.

Palomares, F., Godoy, J. A., Piriz, A., O'Brien, S. J. \& Johnson, W. E. (2002). Faecal genetic analysis to determine the presence and distribution of elusive carnivores: design and feasibility for the Iberian lynx. Mol. Ecol. 11: 2171-2182.

Posada, D. \& Crandall, K. A. (1998). MODELTEST: testing the model of DNA substitution. Bioinformatics 14: 817-818.

Rau, J. \& Gantz, A. (2001). Fragmentation of the native rainforest of southern Chile: effects of the area and shape on the biodiversity of birds. Bol. Soc. Biol. Concepción, Chile 72: 109-119.

Redford, K. H. \& Eisenberg, J. F. (1992). Mammals of the Neotropics, the Southern cone: Chile, Argentina, Uruguay, Paraguay, vol. 2. Chicago: University of Chicago Press.

Reed, J. Z., Tollit, D. J., Thompson, P. M. \& Amos, W. (1997). Molecular scatology: the use of molecular genetic analysis to assign species, sex and individual identity to seal faeces. Mol. Ecol. 6: 225-234.

Sambrook, J., Fritsch, E. F. \& Manatis, T. (1989). Molecular cloning, a laboratory manual. New York: Coldspring Harbor Laboratory Press.

Smith, D. A., Ralls, K., Davenport, B., Adams, B. \& Maldonado, J. E. (2001). Canine assistants for conservationists. Science 291: 435 435.

Swofford, D. L. (2002). PAUP*. Phylogenetic analysis using parsimony (*and other methods). Version 4. Sunderland, MA: Sinauer Associates.

Tannerfeldt, M., Elmhagen, B. \& Angerbjorn, A. (2002). Exclusion by interference competition? The relationship between red and arctic foxes. Oecologia 132: 213-220.

Vilà, C., Amorim, I. R., Leonard, J. A., Posada, D., Castroviejo, J., Petrucci-Fonseca, F. Crandall, K. A., Ellegren, H. \& Wayne, R. K. (1999). Mitochondrial DNA phylogeography and population history of the grey wolf Canis lupus. Mol. Ecol. 8: 2089-2103.

Villagrán, C. (1988). Late Quaternary vegetation of Southern Isla Grande de Chiloé, Chile. Quat. Res. 29: 294-306.

Wilson, D. E. \& Reeder, D. M. (Eds) (1993). Mammal species of the world, a taxonomic and geographic reference. 2nd edn. Washington D.C: Smithsonian Institution Press.

Yahnke, C. J., Johnson, W. E., Geffen, E., Smith, D., Hertel, F., Roy, M. S., Bonacic, C. F., Fuller, T. K., Van Valkenburgh, B. \& Wayne, R. K. (1996). Darwin's fox: a distinct endangered species in a vanishing habitat. Conserv. Biol. 10: 366-375. 